EUROPEAN ORGANIZATION FOR NUCLEAR RESEARCH

European Laboratory for Particle Physics

\title{
CRYOGENIC PRESSURE CALIBRATION FACILITY USING A COLD FORCE REFERENCE
}

\author{
T. Bager, J. Casas and L. Metral
}

\begin{abstract}
Presently various commercial cryogenic pressure sensors are being investigated for installation in the LHC collider, they will eventually be used to assess that the magnets are fully immersed in liquid and to monitor fast pressure transients.

In the framework of this selection procedure, a cryogenic pressure calibration facility has been designed and built. It is based on a cryogenic primary pressure reference made of a bellows that converts the pressure into a force measurement. For that, a shaft transfers this force to a precision force transducer at room temperature. Knowing the liquid bath pressure and the surface area of the bellows, the pressure applied to the transducers under calibration is calculated; corrections due to thermal contraction are introduced. To avoid loss of force in the bellows wall, its length is maintained constant; a cold capacitive displacement sensor measures this. The calibration temperature covers $1.5 \mathrm{~K}$ to $4.2 \mathrm{~K}$ and the pressure 0 to 20 bar. In contrast with more classical techniques that refer to a pressure reference at room temperature, the method presented in this paper avoid errors due to the uncertainty on the hydrostatic head calculation, to thermoacoustic oscillations and to pressure variation caused by temperature drift along the sensing capillary.
\end{abstract}

LHC Division

Presented at the 1999 Cryogenic Engineering and International Cryogenic Materials Conference (CEC-ICMC'99), 12-16 July 1999, Montreal, Canada

\footnotetext{
Administrative Secretariat

LHC Division

CERN

CH - 1211 Geneva 23

Switzerland

Geneva, 1 December 1999
} 


\title{
CRYOGENIC PRESSURE CALIBRATION FACILITY USING A COLD FORCE REFERENCE
}

\author{
T. Bager, J. Casas and L. Metral \\ LHC Division \\ CERN, European Organization for Nuclear Research \\ 1211 Geneva 23, Switzerland
}

\begin{abstract}
Presently various commercial cryogenic pressure sensors are being investigated for installation in the LHC collider, they will eventually be used to assess that the magnets are fully immersed in liquid and to monitor fast pressure transients.

In the framework of this selection procedure, a cryogenic pressure calibration facility has been designed and built. It is based on a cryogenic primary pressure reference made of a bellows that converts the pressure into a force measurement. For that, a shaft transfers this force to a precision force transducer at room temperature. Knowing the liquid bath pressure and the surface area of the bellows, the pressure applied to the transducers under calibration is calculated; corrections due to thermal contraction are introduced. To avoid loss of force in the bellows wall, its length is maintained constant; a cold capacitive displacement sensor measures this. The calibration temperature covers $1.5 \mathrm{~K}$ to $4.2 \mathrm{~K}$ and the pressure 0 to 20 bar. In contrast with more classical techniques that refer to a pressure reference at room temperature, the method presented in this paper avoid errors due to the uncertainty on the hydrostatic head calculation, to thermoacoustic oscillations and to pressure variation caused by temperature drift along the sensing capillary.
\end{abstract}

\section{INTRODUCTION}

The test setup is shown in Figure 1.

\section{Cryostat}

The cryostat has two liquid helium (LHe) reservoirs in the same vacuum vessel. The outer reservoir is shaped like a cylindrical shell, it is continuously filled with LHe at $4.2 \mathrm{~K}$ and acts as a thermal screen for the inner one. A cryogenic valve (18) is used for filling the inner reservoir.

The inner reservoir dimensions are $\varnothing 30 \mathrm{~cm} \times 1 \mathrm{~m}$, a high capacity primary pump (8) regulates its saturated LHe temperature between 1.5 and $4.2 \mathrm{~K}$. The saturation pressure is measured with a high accuracy pressure sensor (7). 


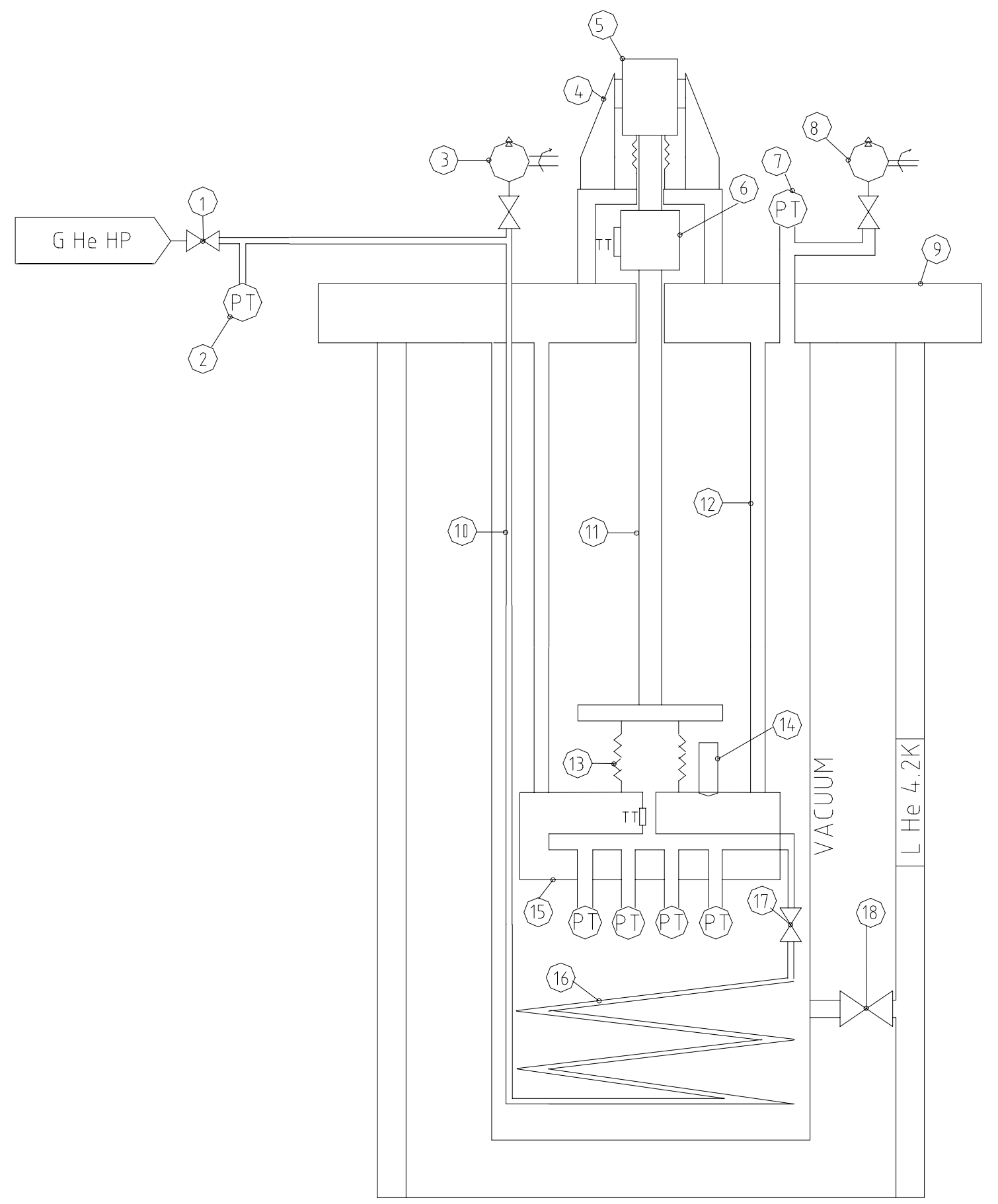

Figure 1. Schematic view of the cryostat

\section{Pressurised test volume}

A gaseous helium (GHe) cylinder at $20 \mathrm{MPa}$ is connected to a pressure regulator (1) resulting in a variable test pressure of $0.1-2 \mathrm{MPa}$. Sub-atmospheric pressures are obtained by means of a primary vacuum pump (3). A capillary (10) is used as hydraulic connection between the warm and cold parts of the experiment and its pressure is always monitored by a high accuracy warm pressure reference (2). The capillary is wound into a helical heat exchanger (16) to cool the helium entering the test volume, which can be isolated by a cryogenic shut-off valve (17).

The distribution flange (15) is made of two 316L stainless steel (SS) disks welded together and it is attached to the main flange (9) by metallic tubes (12). Threaded holes are 
machined in the distribution flange allowing the installation of cryogenic pressure sensors. A bellows (13) is used to convert the inner pressure into a force that is measured with a warm force transducer (6). Risk of buckling imposes a minimum value to the bellows stiffness. The bellows length is measured with a capacitive sensor (14) and it is maintained constant by a linear actuator (5).

\section{MECHANICAL CONSIDERATIONS}

\section{Pressure-to-force conversion}

The bellows is made of electrodeposited nickel (Ni) and has two 316L SS end caps. The effective end cap surface area and the bellows inner and outer pressure determine the force transferred through the shaft (11) that by design is limited to about $1060 \mathrm{~N}$.

The effective surface area is measured in warm conditions and thermal contraction effects are taken into account when operating in cryogenic conditions. With liquid helium the correction factor for effective surface area is:

$$
\begin{aligned}
\frac{A_{316 L, 4 K}}{A_{316 L, 293 K}} & =\left(1-\int_{4 K}^{293 K} d l / l\right)^{2}=\left(1-3.31 \times 10^{-3}\right)^{2} \\
& =0.9934
\end{aligned}
$$

\section{Alignment}

A critical source of uncertainty is the alignment of shaft, bellows and force transducer. The bellows end-cap is aligned by design with the shaft (11), a transversal displacement of $0.35 \mathrm{~mm}$ of the shaft end-cap position is observed when varying the bellows inner pressure from vacuum to $2 \mathrm{MPa}$. This corresponds to an angular variation of about $0.021^{\circ}$ that results in a negligible correction. At cryogenic temperatures it is assumed lower due to higher stiffness.

Torque is minimised since shaft (11) and bellows assembly (13) are not attached to each other by a fixed connection. At low force the bellows is almost free to rotate without transferring torque to the load cell. No shaft rotation is observed during pressurising at $293 \mathrm{~K}$.

\section{Elastic deformation}

Ideally the bellows length should be maintained constant because its finite stiffness is a source of uncertainty. However elastic deformations are unavoidable and their effects should be investigated and compensated if necessary in the load cell, the shaft, the support tubes and the actuator support.

The shaft and support tubes are made of respectively one and three 316L SS tubes. The actuator support consists of three tubes, two are made of 316L SS and one of aluminium.

The elastic compression/expansion is calculated by:

$$
\Delta L=\frac{L \times F}{A \times E}
$$

where $\Delta \mathrm{L}$ is the elastic expansion, $\mathrm{A}$ the effective cross section area, $\mathrm{F}$ the force and $\mathrm{E}$ the modulus of elasticity. Table 1 shows the results for each critical component, a load cell expansion of $108 \mu \mathrm{m}$ is deduced from manufacturer data. 
Table 1. Mechanical characteristics of force transmission components.

\begin{tabular}{|c|c|c|c|c|c|}
\hline & Shaft & Support tubes & $\begin{array}{l}\text { Actuator } \\
\text { support } 1\end{array}$ & $\begin{array}{l}\text { Actuator } \\
\text { support } 2\end{array}$ & $\begin{array}{l}\text { Actuator } \\
\text { support } 3\end{array}$ \\
\hline Force & $1058 \mathrm{~N}$ & $1058 \mathrm{~N}$ & $1058 \mathrm{~N}$ & $1058 \mathrm{~N}$ & $1058 \mathrm{~N}$ \\
\hline Tube length & $970 \mathrm{~mm}$ & $810 \mathrm{~mm}$ & $100 \mathrm{~mm}$ & $100 \mathrm{~mm}$ & $100 \mathrm{~mm}$ \\
\hline Tube cross section & $\varnothing 28 x 1$ & $3 *(\varnothing 16 x 0.5)$ & $\varnothing 70 \times 2$ & $\varnothing 100 \times 2$ & $\varnothing 70 \times 3$ \\
\hline Worst case modulus & $195 \mathrm{GPa}$ & $195 \mathrm{GPa}$ & $195 \mathrm{GPa}$ & $195 \mathrm{GPa}$ & $70 \mathrm{GPa}$ \\
\hline $\begin{array}{l}\text { Calculated max elastic } \\
\text { expansion of tubes at full load }\end{array}$ & $62 \mu \mathrm{m}$ & $60 \mu \mathrm{m}$ & $1.3 \mu \mathrm{m}$ & $0.9 \mu \mathrm{m}$ & $3.5 \mu \mathrm{m}$ \\
\hline
\end{tabular}

\section{Thermal deformations}

Thermal contraction is also a source of uncertainty and the main contributors are the support tubes, the shaft (both made of SS) and the bellows. A first approximation is to calculate the thermal contraction difference of $\mathrm{Ni}$ and $316 \mathrm{~L}$ over the bellows length of $13.9 \mathrm{~mm}$.

$$
\begin{gathered}
\Delta L_{316 L}=\int_{4 K}^{293 K} d l / l \times L=3.31 \times 10^{-3} \times 13.9=46 \mu m \\
\Delta L_{N i}=\int_{4 K}^{293 K} d l / l \times L=2.30 \times 10^{-3} \times 13.9=32 \mu \mathrm{m} \\
\Delta L_{\text {thermal }}=\Delta L_{316 L}-\Delta L_{N i}=14 \mu \mathrm{m}
\end{gathered}
$$

\section{Overall deformation}

The total deflection of the construction is due to the additive effects of elastic and thermal deformation:

$$
\Delta L_{\text {total }}=\Delta L_{\text {thermal }}+\Delta L_{\text {elastic }}=249 \mu \mathrm{m}
$$

Without any compensation, such variation in the bellows length would result in part of the force being taken by the stiffness of the bellows wall. At room temperature this force can be estimated by using manufacturer data:

$$
F_{\text {bellows wall }, 293 \mathrm{~K}}=\text { springrate }_{\text {bellows }, 293 \mathrm{~K}} \times \Delta L_{\text {total }}=11 \mathrm{~N}
$$

This effect might result in an uncertainty of $1 \%$. At cryogenic temperatures the bellows stiffness is higher and it is difficult to implement a compensation algorithm. In consequence a capacitive displacement sensor and a linear actuator are used to maintain the bellows length constant to within $\pm 5 \mu \mathrm{m}$. When operating in LHe, the displacement sensor output should be corrected by approximately $5 \%$ as shown in Table 2.

Table 2. Relative dielectric constant in various relevant media

\begin{tabular}{cc}
\hline Media & Relative dielectric constant \\
\hline air, $300 \mathrm{~K}$ & 1.0005 \\
LHe, $4.2 \mathrm{~K}$ & 1.049 \\
LHe, $1.8 \mathrm{~K}$ & 1.057 \\
\hline
\end{tabular}




\section{OPERATION PRINCIPLE}

\section{Setting the initial bellows position}

Since the bellows is not attached mechanically to the shaft, it is operated with a slight pre-compression, and the applied force through the shaft is always oriented in the same direction independently of the operating temperature. The compression of the bellows is obtained by manipulating the linear displacement actuator while monitoring the force transducer. With a $\Delta \mathrm{p}$ of $0.1 \mathrm{MPa}$, a springrate of $45 \mathrm{~N} / \mathrm{mm}^{2}$ and an area of $529 \mathrm{~mm}^{2}$, the minimal required pre-compression is as a first approximation:

$$
\text { Bellows compression }_{\max }=\frac{\Delta p \times A_{\text {bellows }}}{\text { springrate }_{\text {bellows }}}=1.2 \mathrm{~mm}
$$

By taking a safety margin of about $20 \%$ the actual pre-compression is $1.4 \mathrm{~mm}$, thus the resulting compression force is $9 \mathrm{~N}$, thus reducing the force transducer dynamic range by $0.08 \%$.

\section{Bellows effective area}

The bellows effective surface area for converting pressure into force is determined at room temperature. In this case the warm pressure reference is used and the cryogenic shutoff valve is open. A set of measurements is taken and the best linear fit between measured pressure and force (Figure 2) is used for determining the effective surface area; the repeatability of these measurements is better than $0.15 \%$. Corrections are used to take into account thermal contraction.

\section{Operation at cryogenic temperatures}

When calibrating a set of cryogenic sensors the pressurized volume is gradually filled with gaseous helium until a given pressure setpoint (measured by the warm pressure reference) is reached. During the filling, the bellows length is monitored by the capacitive sensor and is maintained constant by means of the linear displacement actuator. The cryogenic shut-off valve is then closed and a combined measure of the force transducer, inner cryostat pressure and LHe level of the inner reservoir is done. The pressurized helium temperature is measured by using a resistance thermometer calibrated between $1.6 \mathrm{~K}$ and $300 \mathrm{~K}$. Pressure sensors under test are energized according to manufacturers recommendations (usually $10 \mathrm{~V}_{\mathrm{DC}}$ ) and their outputs recorded.

The applied pressure is calculated by:

$$
p_{\text {sensor }}=\frac{F_{L C}}{A_{\text {bellows area }}}+p_{\text {inner cryostat }}+p_{\text {liquid head }}
$$

The liquid level head contributes with a pressure of (see Table 3):

$$
p_{\text {liquid head }}=L_{\text {LHe }} \times g \times \rho_{\text {LHe }}
$$


Table 3. Pressure formed by liquid head

\begin{tabular}{ccc}
\hline $\mathrm{p}_{\text {liquid head }}$ & $\mathrm{L}=10 \mathrm{~cm}$ & $\mathrm{~L}=40 \mathrm{~cm}$ \\
\hline $\mathrm{T}=4.2 \mathrm{~K}$ & $0.12 \mathrm{kPa}$ & $0.49 \mathrm{kPa}$ \\
$\mathrm{T}=1.8 \mathrm{~K}$ & $0.14 \mathrm{kPa}$ & $0.57 \mathrm{kPa}$ \\
\hline
\end{tabular}

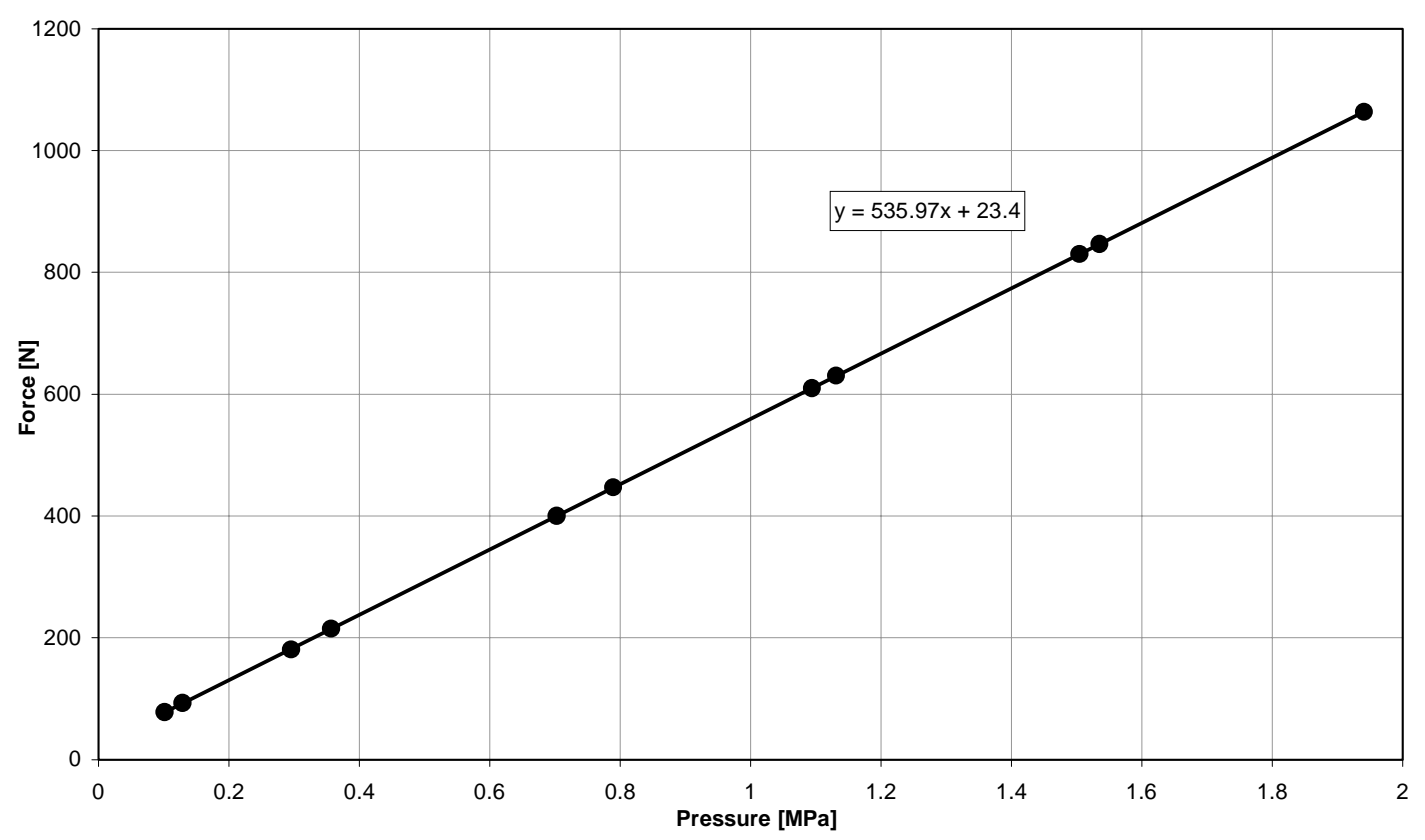

Figure 2. Calculation of bellows area

The pressure inside the test volume is varied from vacuum to the maximum range of the pressure sensors or $2 \mathrm{MPa}$, whatever is lower. A measurement in vacuum conditions permits elimination of bellows effects due to the pre-compression and to the dependence with temperature of bellows stiffness.

Sensors under test are located $10 \mathrm{~cm}$ lower than bellows, thus for pressures above saturation pressure the liquid head inside the pressurised chamber is $0.12 / 0.14 \mathrm{kPa}$, which must be added to sensor pressure. For pressures below saturation pressure the hydrostatic head consists of gas only and is below $16 \mathrm{~Pa}$.

\section{Apparatus}

A MacIntosh ${ }^{\mathrm{TM}}$ computer running LabVIEW $^{\mathrm{TM}}$ is used for control and data acquisition. IEEE-488 is used for communication between the computer and the instruments. A digital multi-meter with an integrated 20-channel scanner is used for monitoring the temperatures and other diagnostic instruments. The pressure reference is directly read through the bus.

All the LHC-prototype pressure sensors have a membrane for separating a reference vacuum chamber from the pressurized media. The displacement of the membrane is a function of the applied pressure. Depending on the sensor, this displacement is measured by strain gauges, reluctance coils or optical techniques.

For strain gauges an $\mathrm{HBM}^{\mathrm{TM}}$ ML10 amplifier was used. This instrument is used for measuring the force transducer and up to 5 pressure sensors simultaneously. The excitation voltage is typically $10 \mathrm{~V}_{\mathrm{DC}}$ and the accuracy is $0.03 \%$ of full scale.

For reluctance coils and optical type pressure sensors, a specific instrument for conditioning the output is supplied by the sensor manufacturer. In such cases it is not 
Table 4. Combined errors of instruments.

\begin{tabular}{cccccc}
\hline $\begin{array}{c}\text { Bellows } \\
\text { area }\end{array}$ & $\begin{array}{c}\text { Pressure inner } \\
\text { cryostat }\end{array}$ & $\begin{array}{c}\text { Force } \\
\text { measurement }\end{array}$ & Liquid head & $\begin{array}{c}\text { Bellows } \\
\text { position }\end{array}$ & $\begin{array}{c}\text { Conditioner for } \\
\text { sensors under test }\end{array}$ \\
\hline $0.17 \%$ & $0.29 \mathrm{kPa}(\sim 145 \mathrm{ppm})$ & $0.12 \% \mathrm{FS}$ & $29 \mathrm{~Pa}(\sim 15 \mathrm{ppm})$ & $20 \mathrm{~nm}$ & $300 \mathrm{ppm} \mathrm{FS}$ \\
\hline
\end{tabular}

possible to discriminate whether the uncertainties come from the electronic unit or the sensor itself.

The pressure inside the capillary is measured by a Mensor ${ }^{\mathrm{TM}} 2106$ warm pressure reference with a range of 0 to $2.6 \mathrm{MPa}$ and an uncertainty of $0.65 \mathrm{kPa}$. The liquid helium level is measured by using a superconducting probe with an uncertainty of about $2 \mathrm{~cm}$. The inner reservoir pressure is measured by an industrial pressure transducer and the $\mathrm{HBM}^{\mathrm{TM}}$ amplifier, the uncertainty is $0.29 \mathrm{kPa}$.

The linear displacement actuator is programmed via RS232 by a computer and controlled during operation by a keypad. The maximal displacement is $20 \mathrm{~mm}$, the resolution better than $1 \mu \mathrm{m}$ and has backlash of about $12 \mu \mathrm{m}$. This actuator is used regularly during cool-down and warm-up requiring displacement of up to $200 \mu \mathrm{m}$.

Instrument errors are summarised in Table 4.

\section{EXPERIMENTAL RESULTS}

\section{Operation at 4.2 K}

Preliminary tests have been performed at $4.2 \mathrm{~K}$ and four different types of pressure sensors have been tested. A relatively good linearity between sensor output and applied pressure is observed. The deviation from best straight line is for all sensors less than $3 \mathrm{kPa}$ $(\sim 0.15 \%$ FS $)$. See Figure 3. A short overview of sensor types tested can be found in Table 5 .

The accuracy obtained has been limited by a leak in the cryogenic shut-off valve that result in oscillations and drift in the force transducer. The seal of this valve will be changed and we expect its leak-tightness not to be a limiting factor in the ultimate uncertainty that can be obtained with this calibration facility.

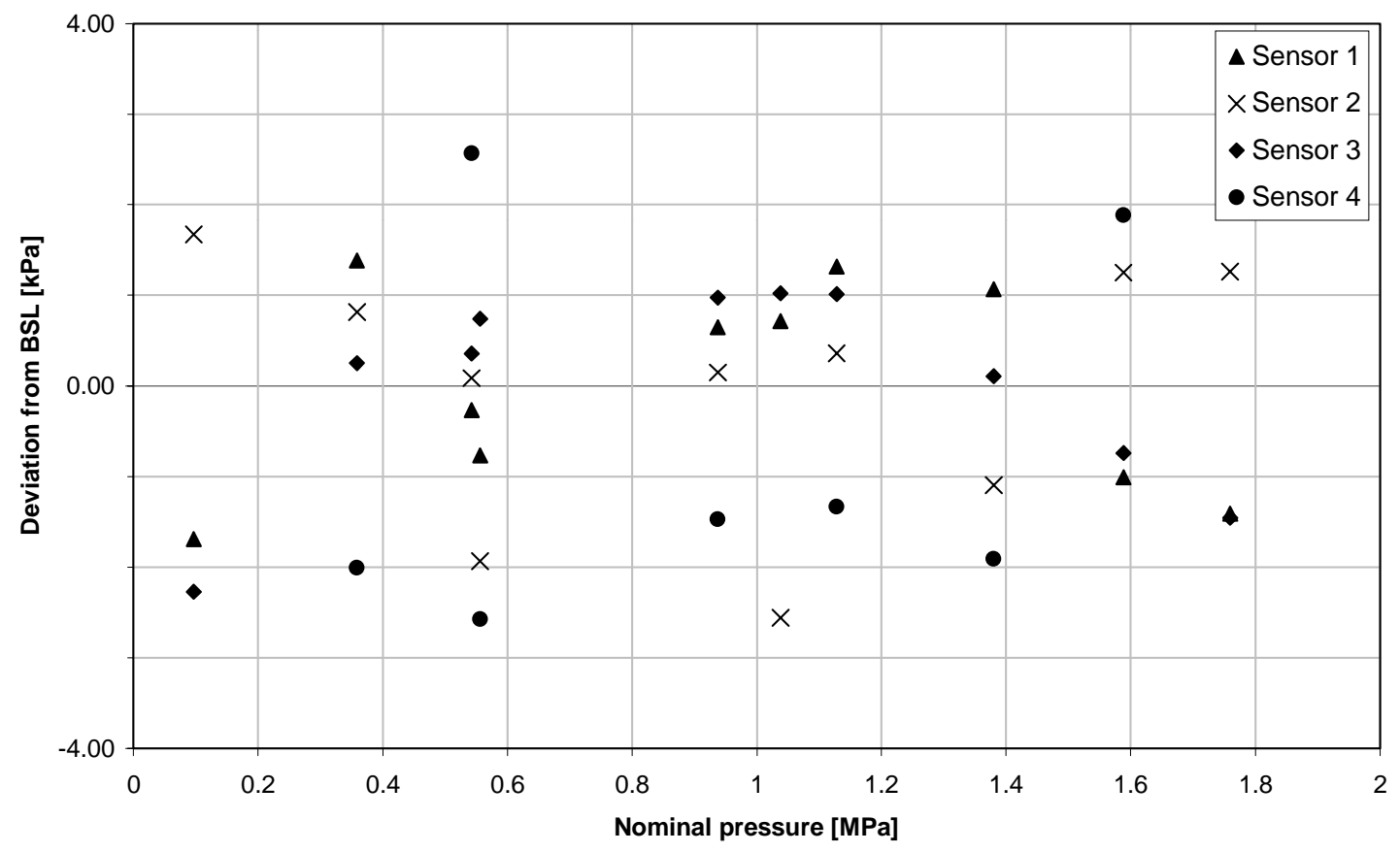

Figure 3. Sensors under test, deviation from best straight line 
Table 5. Main characteristics of sensors tested

\begin{tabular}{ccccc}
\hline & Sensor 1 & Sensor 2 & Sensor 3 & Sensor 4 \\
\hline Diaphragm & metal (w 1.4542) & metal (15.5PH) & $\mathrm{SiO}_{2}$ & Metal (Inconel) \\
Sensing principle & Strain gauge & Strain gauge & Strain gauge & Inductive, \\
Excitation & metallic resistance & metallic resistance & metallic resistance & brass target \\
Nominal output @ $\mathrm{FS}$ & $10 \mathrm{~V}_{\mathrm{DC}}, 5 \mathrm{k} \Omega$ & $10 \mathrm{~V}_{\mathrm{DC}}, 1.25 \mathrm{k} \Omega$ & $10 \mathrm{~V}_{\mathrm{DC}}, 0.7 \mathrm{k} \Omega$ & $56 \mathrm{kHz} \mathrm{AC}$ \\
\hline
\end{tabular}

Note (1): Output of dedicated signal conditioner

\section{CONCLUSION}

A facility for calibrating cryogenic pressure sensors has been fabricated and commissioned. It is based in a primary cryogenic pressure reference made of a bellows and a piston transmitting the resulting force into a high-accuracy force transducer, in order to eliminate uncertainties related to an unknown pressure head inside the sensing capillary. The pressurized volume can be isolated from the capillary strongly reducing the effects of pressure oscillations that can be observed with the warm pressure reference.

\section{ACKNOWLEDGMENT}

Thanks for good ideas to $\mathrm{Ph}$. Lebrun, CERN, for manufacturing components to $\mathrm{P}$. Portier and J. Beltron, CERN, for help on operating to P. Romand, CERN.

\section{REFERENCES}

H.E.Krex. "Maskinståbi”, Teknisk Forlag, København (1986).

J.G. Weisend II. "Handbook of Cryogenic Enginering", Taylor \& Francis, Philadelphia (1998).

Hepak Software, Cryodata Inc., Niwot, Co (1993). 